\title{
Challenges and opportunities for web-shared publication of quality-assured life cycle data: the contributions of the Life Cycle Data Network
}

\author{
Marco Recchioni ${ }^{1} \cdot$ Gian Andrea Blengini ${ }^{1,2}$. \\ Simone Fazio ${ }^{1} \cdot$ Fabrice Mathieux $^{1} \cdot$ David Pennington $^{1}$
}

Received: 22 January 2015 / Accepted: 18 May 2015 /Published online: 16 June 2015

(C) The Author(s) 2015. This article is published with open access at Springerlink.com

\begin{abstract}
Purpose The European Commission's Integrated Product Policy Communication, 2003, defined Life Cycle Assessment (LCA) as the 'best framework for assessing the potential environmental impacts of products'. Since then, the use of LCA and life cycle approaches has been developing in a wide range of European policies, and its use has also significantly grown in business. Increasing the availability of quality-assured Life Cycle Inventory (LCI) data is the current challenge to ensure the development of LCA in various areas. Methods One solution to increase availability is to use LCI data from multiple database sources but under the condition that such LCI data are fully interoperable.

Results and discussion This paper presents original solutions and recent achievements towards increased availability, quality and interoperability of life cycle inventory data, developed through European Commission-led activities and based on wide stakeholder consultation and international dialogue. An overview of related activities, such as the International Reference Life Cycle Data System (ILCD), the European Reference Life Cycle Database (ELCD) and the ILCD Entry-Level quality requirements are presented. The focus is then on the Life Cycle Data Network (LCDN).
\end{abstract}

Responsible editor: Martin Baitz

Gian Andrea Blengini

blengini@polito.it; gianandrea.blengini@jrc.ec.europa.eu

1 European Commission, Joint Research Centre, Institute for Environment and Sustainability, T.P. 290, 21027 Ispra, Va, Italy

2 Politecnico di Torino, Corso Duca degli Abruzzi 24, 10129 Torino, Italy
Conclusions A non-centralised data network of LCI datasets complying with minimum quality requirements that was politically launched in February 2014, already includes several database nodes from different worldwide sources and has the potential to contribute to the needs of the international community.

Keywords Data quality - ELCD · Entry-level requirements · LCA $\cdot$ Life cycle data

\section{Introduction}

\subsection{Policy context}

After its debut in the European Commission (EC)'s Integrated Product Policy Communication (European Commission 2003), as 'best framework for assessing the potential environmental impacts of products', Life Cycle Assessment (LCA) has been increasingly used in support of policy and business in the European Union (EU). For instance, in the context of the Directive 2009/28/EC, an LCA-based greenhouse gases (GHG) assessment method is used to promote the use of energy from renewable sources (European Union 2009). LCA results can be used as support for setting ecolabel (European Union 2010) and GPP criteria (European Commission 2008a) in a range of product groups. The use of LCA in application contexts such as, e.g. environmental management system schemes has been promoted in the Sustainable Consumption and Production and Sustainable Industrial Policy (SCP/SIP) Action Plan (European Commission 2008b). LCA is also very important in waste policies, including the Waste Framework Directive (European Union 2008): for example, in its article 4, the directive calls for the identification, using life cycle 
thinking, of the 'options that deliver the best overall environmental outcome; when applying the so-called waste hierarchy. The life cycle approach has also been playing a major role for the implementation of the EU's thematic strategy on the sustainable use of natural resources (European Commission 2005a) and in the thematic strategy on prevention and recycling of waste (European Commission 2005b).

In 2011, the EC launched several flagships. These provide a core focus for policy development. In the flagship initiative 'A Resource-Efficient Europe' and related roadmap (European Commission 2011), life cycle thinking has been stated as one of the engines to boost smart, sustainable and inclusive growth in the EU. In such a context, the EC further engaged in turning consumption and production more sustainable, through 'improving products and changing consumption patterns' and by 'boosting efficient production'. To this aim, beside strengthening the more consolidated product policies (e.g. ecolabel, GPP, Ecodesign Directive), LCA gained further importance as the methodological background to address and develop the Product Environmental Footprint (PEF) and the Organisation Environmental Footprint (OEF) Guides (European Commission 2013a). Both PEF and OEF guides are annexed to the COM Building the Single Market for Green Products (European Commission 2013b) and are intended as references to conduct LCA in the EU. Life cycle thinking is also foreseen in response to the development of indicators at the EU-scale in relation to the social and environmental benefits and burdens associated with trade and consumption (European Commission 2012).

Bearing in mind that LCA is an evolving field, with diverse methodological choices (Finnveden et al. 2009), many sector and product-specific guidance documents are expected to be developed, in the short run, to best support business and other stakeholders in their environmental footprint assessments. For example, the European Food Sustainable Consumption and Production (SCP) Round Table launched in 2013 the EnviFood Protocol that is an assessment method for food and drink products in line with EF Guides (European Commission 2013a). This builds on guiding principles agreed amongst main stakeholder representatives of the food and drink supply chains, providing an initial guidance to facilitate coherent and science-based assessments of food and drink products. The key principles are aligned with, and promote, life cycle thinking.

Initiatives such as PEF and OEF can be considered a significant step towards improved measurement and communication of the environmental performance of products and organisations in relation to meeting specific policy and business interests. EF guides build on ISO 14044 requirements and facilitate reproducibility and comparability through the establishment of data quality requirements that are further detailed in the Product Environmental Footprint Category Rules (PEFRCs) and the Organisation Environmental Footprint Sectorial Rules (OEFSRs) (Galatola and Pant 2014).

The paragraphs above show that LCA-based methodologies and tools have been developing fast in recent years, including building on and strengthening the importance of ISO 14044. However, the availability of quality-assured Life Cycle Inventory (LCI) data still represents a major bottleneck to a broader use of LCA in business and in policy. Lack of adequate quality data can, in fact, adversely affect LCA repeatability, reliability and comparability, as it was already pointed out in 2002 by Bjorklund (2002).

Although from the data supply side, pro-active business associations recognise the importance of providing highquality consistent data that reflects the life cycle reality of their goods and services, the supply of such data is supported by a growing body of experts in consultancies (mainly small- and medium-sized enterprises, SMEs) and by various research groups; with altogether at least 100 small life cycle service providers in Europe and beyond. There are now at least 25 broad LCA databases and 40 LCA software tools that are available (Sanfélix et al. 2013). This increasing complexity creates technical and methodological issues not always easy to be managed.

\subsection{Scientific and technical context}

Increasing the availability of quality-assured LCI data is a key challenge to ensure the uptake of LCA in various areas of policy and business. One solution to increase availability is to use LCI data from multiple database sources (Suh et al. 2013). This appears to align well to worldwide community needs, where data are foreseen to come from many companies, associations, governments and research projects. However, this also requires that LCI data are fully interoperable. Equally, data must have sufficient quality to facilitate defendable LCAs. An alternative is to develop large, databases worldwide in isolation, reflecting somewhat practice-to-date, resulting in duplication, as well as leading to differences that make combination costly and/or infeasible.

Data from different database sources can be considered interoperable when, if used in LCA studies, they lead to results that are coherent with the defined goal and scope. In fact, when two or more LCI databases are combined in an LCA study, the practitioner has to ensure that the underlying assumptions, methods and level of completeness (intrinsic properties) are comparable between the databases used (Suh et al. 2013). Intrinsic properties reflect data content and quality, while the use of different data exchange formats and nomenclature of elementary flows (extrinsic properties) is a technical issue when exchanging datasets from multiple databases and 
using different LCA software applications; currently left to the expense and technical competence of users of multiple databases, with associated risks.

In order to enhance datasets interoperability, it is necessary to move towards datasets harmonisation and provide guidance for their coherent use (Frischknecht 2006; Ossés de Eicker et al. 2010; Suh et al. 2013); intergovernmental activities are currently on going on this topic.

Harmonisation of extrinsic properties such as nomenclature and data format is a necessary and highly feasible step that can lead to full compatibility from an information technology (IT) perspective (i.e. a common language spoken). Nomenclature also has an important role from a methodological perspective to facilitate the collection and use of data to be able to calculate impact assessment results using associated models; hence, recommendations are equally vital to ensure appropriate implementation of impact assessment models recommended by authoritative bodies. Similarly, formats provide a structure for vital information that are required by users in relation to their relevance to the goal and scope of a study.

The coherent use of datasets depends on intrinsic properties and the objectives of the LCA study/application. In such a context, the documentation provided together with the inventory plays a key role: LCA practitioners can choose the appropriate LCI datasets only if they have access to a clear and concise documentation of the datasets (JRC 2010) defining, e.g. what process it describes, what are the sources of the raw data, how these data have been manipulated, what has been included and excluded and what are the limitations or exclusions of use for the dataset.

Continual/periodic guidance and harmonisation activities are essential for greater consistency, broadening acceptance, improving data exchange, reducing costs and efficiently highlighting key research needs (Pennington et al. 2007). Moreover, common understanding and rules are required (Frischknecht 2006; Skone and Curran 2005), and there is a growing international consensus that LCI datasets should conform to shared criteria, including methodology, format, review and nomenclature that allow for effective interoperability (Sonnemann and Vigon 2011). It is in such a context of broad international consensus that the so-called Shonan Guidance Principles where created (Sonnemann and Vigon 2011), following a workshop held in Japan in 2011, as a set of recommendations for the development of interoperable LCA databases. In particular, such guidance principles recommend the use of a globally harmonised reference list of elementary flows as the primary condition for interoperability of datasets and databases. Moreover, each dataset needs to be clearly and concisely documented, as mentioned above. Furthermore, according to these principles, uncertainties must be described.
As argued by Suh et al. (2013), building a global LCI database from scratch with a harmonised method and wide process coverage would require significant resources. This statement brings the discussion back to the opportunity of using interoperable datasets from multiple providers in a network of databases. Moreover, facilitating international networking of data, rather than reliance on any single provider, is seen as essential in the 'Shonan Guidance Principles' (Sonnemann and Vigon 2011).

In summary, although LCA databases have been developing globally, the main challenges for satisfactory interoperability and quality assurance still concern the data format and nomenclature of datasets and the documentation. Moreover, several of the 'Shonan Guidance Principles' have not been implemented systematically.

\subsection{Aim of this paper}

This paper presents original solutions and recent achievements towards increased availability, quality and interoperability of Life Cycle Inventory data, obtained through EC-led activities and based on wide stakeholder consultation and international dialogue. The focus is on the Life Cycle Data Network launched in February 2014 by the EC.

An overview of past and recent activities related to the International Reference Life Cycle Data System (ILCD) and the European Reference Life Cycle Database (ELCD), in particular the quality review of a number of its datasets, is presented in section 2. A new development, the Life Cycle Data Network, which aims is to address the challenges identified in section 1.2 concerning data quality assurance and data availability is then presented in section 3. Concluding remarks and perspectives are finally formulated in section 4.

\section{Overview of past EC-led activities on LCI data}

\subsection{Setting up a reference $\mathrm{LCI}$ database for $\mathbf{E U}$}

The Joint Research Centre (JRC) of the European Commission (EC) is a Directorate General (DG); i.e. one of the XXXX DGs that constitute the EC. The JRC is the European Commission's in-house science service which employs scientists to carry out research in order to provide independent scientific advice and support to EU policy.

Since 2005, the JRC has been leading several activities and developed the European Platform on LCA (EPLCA). Through the platform, the commission provides support to its own policies, to member states and to business by promoting the availability of reference and compliant data, reference information and studies (see e.g. (Sanfélix et al. 2013)), as well as recommended methods and guidance documents (EC 
et al. 2010). A key element is stakeholder and international interaction.

Within the EPLCA, a first version of the European Reference Life Cycle Database (ELCD) was released in 2006. Having a European market scope, the ELCD provides key background life cycle data for LCA practitioners and database developers. The database incorporates LCI data from front-running EU-level business associations, as far as possible. This is complemented with other sources for key materials, energy carriers, transport and waste management. These are periodically reviewed. Datasets are typically LCI results with parameterised unit processes for transport services. The respective datasets are officially provided and approved by the named business association or other provider. In June 2009, a second version of the ELCD was released, where the number of LCI datasets with European scope was increased to over 300 (see Table 1). A further update and expansion was completed in February 2013 with the third version of the ELCD. Beyond including additional datasets covering new sectors, several datasets of the third version of the ELCD underwent - and successfully passed - a third party review against specific quality requirements, called 'ILCD entry level requirements', which will be described in the next section.

Figures and features of various versions of the ELCD database are summarised in Table 1.

In order to contribute to increased coherence, the ELCD has adopted the ILCD format and nomenclature. Datasets are therefore using reference elementary flows, units and documentation format, as reported in the provisions of the ILCD Handbook (JRC 2010). The development, documentation and publication of both unit process and aggregated LCI datasets are supported by the ILCD format.

While the ELCD supports the availability of a lot of the core background data used in most LCAs with recommendations, it equally has a focused scope. While the scope is under review, it cannot be comprehensive, nor does it aim to be this. It therefore must also be part of a broader network of data, complementing the wide range of other data and sources that are required to complete LCAs.

\subsection{Setting-up meaningful and practicable data quality requirements}

Having said that facilitating international networking of data, rather than reliance on any single provider is essential, the 'Shonan Guidance Principles' have drawn the 'line in the sand'. However, in order to implement this principle, concrete actions towards interoperability and building such a network have to be undertaken. In this sense, a minimum common quality level and coherence between datasets coming from different sources must be assured, and there is a need to operate with a minimum set of quality requirements (Frischknecht 2006).

In e.g. the ILCD handbook, minimum requirements have been established to provide users with useful information on data quality to guarantee minimum extent of documentation and to facilitate increased methodological consistency amongst datasets. This was built on ISO 14040 through an extensive international stakeholder process, providing further guidance and specification for different application contexts. This includes minimum requirements, the ILCD entry-level requirements. Part of this is a structured review procedure.

To be compliant with the ILCD entry-level requirements, a reviewer should certify the compliance of a dataset against the requirements of each of five compliance areas, as described in Table 2.

After an extensive review of existing formats used by various data providers as well as several meetings involving key stakeholders from around the globe and building on previous UNEP-SETAC-led initiative draft conclusions, the ILCD dataset format was developed to ensure wide compatibility and to allow incorporating the complete documentation within the dataset itself (European Commission 2010). Datasets compliant to the requirement on documentation provide to the users the information needed to assess data quality in a given context, as foreseen in ISO 14040. Moreover, such requirements on documentation can facilitate the use of the dataset in combination with other datasets and ensure consistency in terms of methodological choices such as applied cut-off, solutions for multi-functionality issues and system boundaries definition. From an IT perspective, having a common format

Table 1 Summary of various versions of the ELCD database

\begin{tabular}{llll}
\hline Version of ELCD database & Year of launch & Number of LCI datasets & Quality features \\
\hline ELCD 1 & 2006 & 176 & \\
ELCD 2 & 2009 & 329 & $\begin{array}{l}\text { Compliance with ILCD format and ILCD nomenclature required. } \\
\text { No review process established. } \\
\text { Compliance with ILCD entry-level requirements. } \\
\text { ELCD 3 }\end{array}$ \\
& 2013 & 524 & 223 reviewed datasets, 190 compliant datasets. \\
\hline
\end{tabular}


Table 2 ILCD entry-level requirements, organised in five compliance areas (JRC 2011)

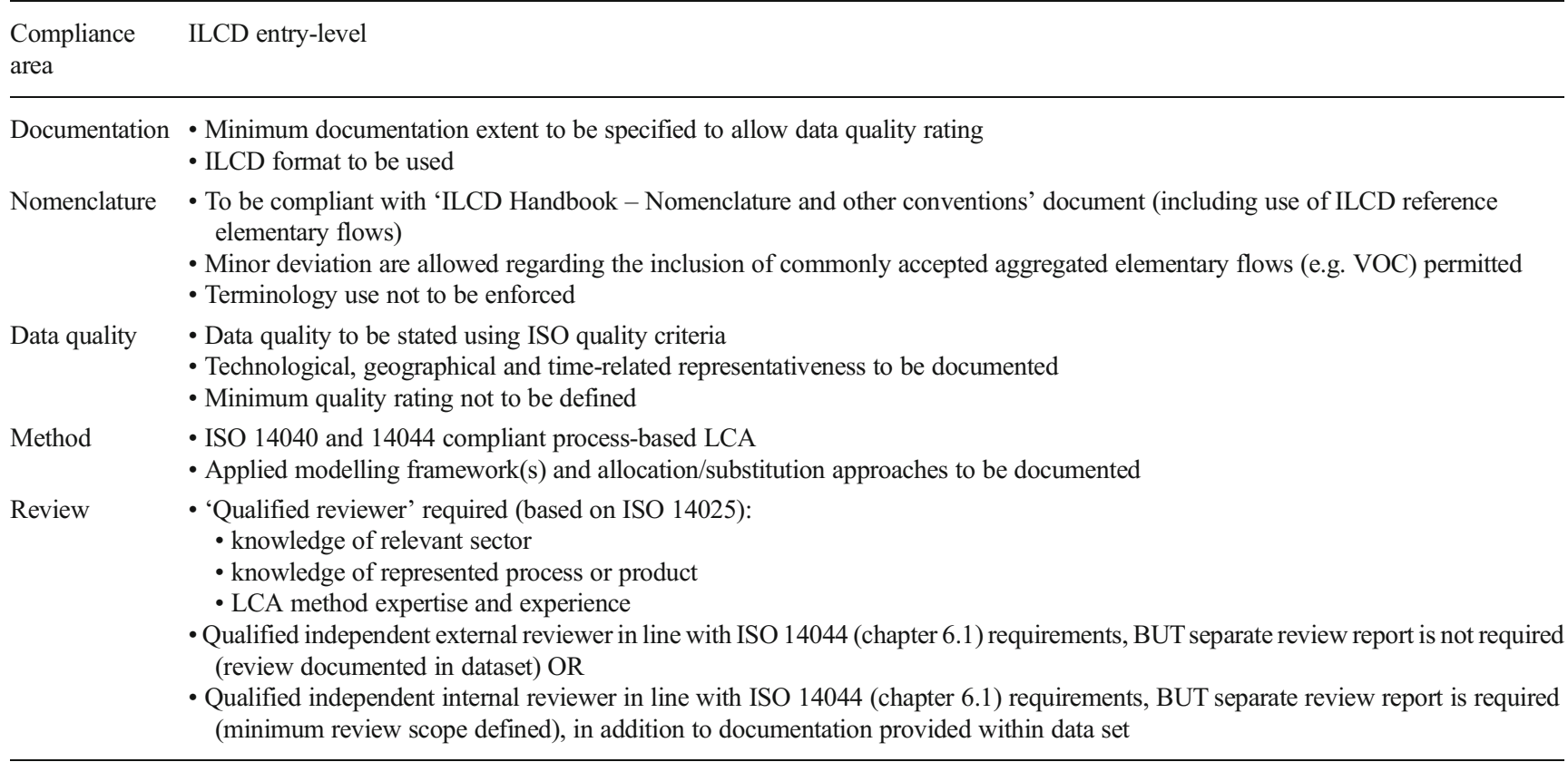

for a minimum set of fields reduces costs to users and potential room for error.

The compliance areas 'data quality' (e.g. data representativeness) and 'method' have been defined according to the ISO and specific documentation requirements. Specific information regarding methodological choices and representativeness must be provided in the datasets. Data, which are collected according to several technical guidance going beyond ISO (e.g. EF guides), can be used together coherently.

The review process aims at transparently communicating dataset quality by making review reports accessible to users, especially in the case of independent internal reviews. Specific requirements on review have been defined to increase the overall robustness of the process. Moreover, in some cases, review reports shall be annexed to the dataset providing additional information to user.

\subsection{Reviewing ELCD 3 against ILCD entry-level requirements}

As highlighted earlier, the third release of the ELCD focused on data quality assurance and consistency. To this aim, between 2011 and 2013, 223 datasets of the ELCD 3.0 have been screened against the ILCD entry-level requirements (see Table 1). These reviewed datasets cover background data of seven sectors, with a time reference from 1996 to 2009 and with a European average geographical and technological representativeness. Datasets to be reviewed have been selected in order to be representative of key sectors such as energy and raw material production and also taking into account data providers' willingness to actively participate in the review process.

The review process involved eight reviewers holding the qualifications described in Table 2 in the 'review' compliance area.

As a result from the review exercise, 190 ILCD entry-level compliant datasets can currently be found in the ELCD 3, where information on dataset quality as well as compliance with the ILCD entry-level requirements can be found in the documentation under the 'validation section'. The review reports (see some examples ${ }^{1,2}$ ) have been attached to datasets and are directly accessible through the European Platform on LCA website.

Several other newly developed datasets on transport and materials are currently being reviewed against the ILCD entry-level requirements and are planned to be published in the next release in 2015 .

According to the review process, more than $86 \%$ of the datasets directly met the criteria expressed by the ILCD Entrylevel requirements.

Observed non-compliances were actually limited to lack of or misleading documentation (13\% of reviewed datasets) and problems with format/nomenclature (1\% of reviewed datasets). Moreover, review reports proved to be a fruitful

\footnotetext{
${ }^{1}$ http://eplca.jrc.ec.europa.eu/ELCD3/resource/sources/ d3960659-e53d-4da9-9eb1-8801b463dd51.xml

${ }^{2}$ http://eplca.jrc.ec.europa.eu/ELCD3/resource/sources/ f412a1a8-6328-4f82-99d6-0e354912ece3.xml
} 
exercise to define key needs for not compliant datasets towards full compliance. The review process was also beneficial because owners of the datasets that did not pass the quality check immediately started a revision of the datasets to improve them.

\section{The Life Cycle Data Network}

\subsection{Main features of the Life Cycle Data Network}

The Life Cycle Data Network (LCDN) consists of a noncentralised database, where several providers are facilitated in sharing data. Such a data network is a concrete action towards the creation of new dynamics, including opening of new data markets, where data availability can be increased in parallel to data quality thanks to well-defined entry-level requirements that assure better interoperability and coherence as well as a convenient basis for comparison of available data. The LCDN is based on an IT infrastructure developed ad hoc, which is provided for free to organisations willing to participate. The IT development has been coordinated by JRC with the support of the Karlsruhe Institute of Technology (KIT) and by the Instituto Brasileiro de Informação em Ciência e Tecnologia (IBICT).
The LCDN was conceived so that datasets in the network can come from any data developer/owner, including international organisation (providing international databases), states (providing national databases), industry associations (providing sectorial databases), business (providing commercial databases), SMEs (providing a few datasets on commercial products/processes) and even research groups (providing a few datasets on innovative processes). The developer/owner is responsible for maintenance and updates of their database, which forms a node in this network.

A two-fold IT infrastructure of the LCDN allows the data to be published under the conditions decided by the data developer (e.g. for free, for fee, via registration, etc.) and allowing data developers to retain the full copyright and independently manage their databases/sets. At the first level of the IT infrastructure, partners publish datasets directly from their own web-based node; at the second level of the infrastructure, the LCDN webpage serves only as searching tool and as reference point providing essential information to users and providers. Once the datasets are self-uploaded into the node (1st level), the node owner can register selected datasets to the so-called LCDN registry (2nd level), only under the condition that ILCD entry-level requirements are met.

The EC JRC has supported the development of the two IT applications on which the LCDN is based on the following: the soda4LCA (1st level) and the LCDN registry (2nd level).
Fig. 1 Overview of current participants in the Life Cycle Data Network at the time of the submission of the paper. Note: the size of the node is proportional to the number of datasets contained in the node

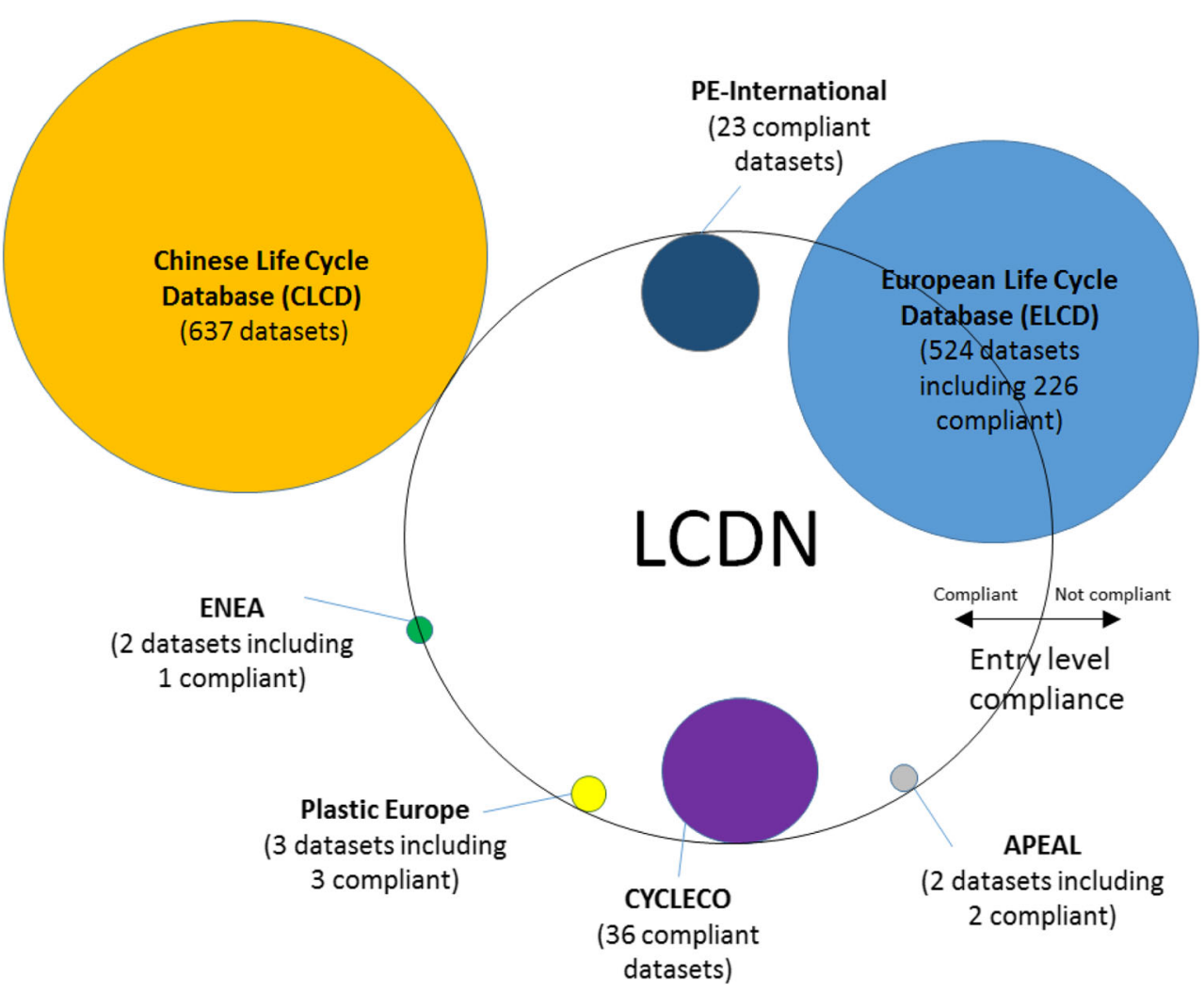


The soda4LCA (service-oriented database application for LCA Kusche et al. 2012) database software is used to publish datasets within each LCDN node, while the LCDN registry serves as an interface and searching tool throughout all the nodes.

\subsection{Current status of the Life Cycle Data Network}

The LCDN has been officially launched on February 6, 2014 by two directorate generals of the EC, DG Joint Research Centre and DG Environment, involving seven initial partners (Fig. 1). Since the launch, several further commitments to participate have been received from key actors in the worldwide LCA community. Discussions are ongoing with other front-runners from governments and business.

The ELCD 3 is participating to the LCDN as 'JRC ELCD node' with the successfully reviewed 190 datasets mentioned in section 2.3. Around 100 other datasets are currently being reviewed against the ILCD Entry-level requirements. All compliant datasets are registered to the LCDN.

\section{Conclusions and perspectives}

Application of LCA in policy and business is rapidly evolving, with further common methodological development potentially playing a key role in this increased uptake and facilitating widespread use in business and policy. The availability of quality-assured data is therefore imperative to the success of this development. The international community has underlined the importance of facilitating the interoperability of data from multiple data sources through guidance development and harmonisation.

The European Commission's efforts and past achievements concerning life cycle data that allowed the development of the ILCD format and nomenclature have been highlighted in the paper. Moreover, recent achievements have been detailed in the article. For example, ILCD entry-level requirement are key towards creation and implementation of a common language for LCI data and are essential support for the end-users of LCI data. It was moreover shown how compliance with ILCD entry-level requirements supports a consistent LCA framework application through the definition of common minimum specifications for LCI datasets intrinsic properties and, hence, enables the coherent use of LCI data. The establishment of the ELCD review process against the ILCD entrylevel requirements is another concrete step towards qualityassurance of LCI datasets. Finally, the LCDN is a contribution to the implementation of the 'Shonan Guidance Principles towards emancipating the LCA community from the reliance on any single provider. One of the aims is to enlarge the number of nodes registered to the LCDN and to encourage the development of ILCD entry-level compliant datasets.
JRC is also currently running projects focused on increasing interoperability between the ILCD data format and other available ones. Moreover, an ongoing initiative aims at defining a common elementary flows nomenclature, through establishing a working group and involving advisory group members of the EPLCA and some international partners. Intense international level dialogue on these aspects is currently taking place.

JRC is contributing to international processes where our developments are examples of good practice that contribute to advances interoperability.

Acknowledgments This work has been partly financially supported by DG ENVIRONMENT of the European Commission. We gratefully thank Clemens Duepmeier, Marco Guaita, Oliver Kusche and Marc-Andree Wolf for their contributions in the conceptual and the technical development of the Life Cycle Data Network.

Open Access This article is distributed under the terms of the Creative Commons Attribution 4.0 International License (http:// creativecommons.org/licenses/by/4.0/), which permits unrestricted use, distribution, and reproduction in any medium, provided you give appropriate credit to the original author(s) and the source, provide a link to the Creative Commons license, and indicate if changes were made.

\section{References}

Bjorklund AE (2002) Survey of approaches to improve reliability in LCA. Int J Life Cycle Assess 7:64-72

EC, JRC, IES (2010) ILCD handbook: general guide for life cycle assessment-detailed guidance, European Commission, Joint Research Centre. Institute for Environment and Sustainability, Luxembourg

EC, JRC, IES (2011) International Reference Life Cycle Data System (ILCD) Data Network: compliance rules and entry-level requirements, European Commission, Joint Research Centre. Institute for Environment and Sustainability, Luxembourg

European Union (2008) Directive 2008/98/EC of the European Parliament and of the Council of 19 November 2008 on waste and repealing certain directives, Official Journal of the European Union, $22 / 11 / 2008$

European Union (2009) Directive 2009/28/EC of the European Parliament and of the Council on the promotion of the use of energy from renewable sources and amending and subsequently repealing Directives 2001/77/EC and 2003/30/EC, Official Journal of the European Union L 140, 5 June 2009, pp. 16-47

European Union (2010) Regulation (EC) No 66/2010 of the European Parliament and of the Council of 25 November 2009 on the EU Ecolabel, Official Journal of the European Union

European Commission (2003) COM (2003) 302: communication from the Commission to the Council and the European Parliament-integrated product policy — building on environmental life-cycle thinking Brussels

European Commission (2005a) COM(2005) 670 final: thematic strategy on the sustainable use of natural resources, Brussels

European Commission (2005b) COM(2005) 666 final: thematic strategy on the prevention and recycling of waste, Brussels

European Commission (2008a) COM(2008) 400: Communication from the Commission to the European Parliament, the 
Council, the European Economic and Social Committee and the Committee of the Regions: public procurement for a better environment, Brussels

European Commission (2008b) COM(2008) 397: Communication from the Commission to the European Parliament, the Council, the European Economic and Social Committee and the Committee of the Regions on the sustainable consumption and production and sustainable industrial policy action plan, Brussels

European Commission (2010) Joint Research Centre - Institute for Environment and Sustainability: International Reference Life Cycle Data System (ILCD) Handbook - Specific guide for Life Cycle Inventory data sets. EUR 24709 EN. Publications Office of the European Union. Luxembourg

European Commission (2011) COM(2011) 571: roadmap to a resource efficient Europe, Brussels

European Commission (2012) Life cycle indicators basket-of-products: development of life cycle based macro-level monitoring indicators for resources, products and waste for the EU-27. European Commission, Joint Research Centre, Institute for Environment and Sustainability

European Commission (2013a) Official journal of the European Union, 56, 4 May 2013, Commission Recommendation of 9 April 2013 on the use of common methods to measure and communicate the life cycle environmental performance of products and organisations, Brussels

European Commission (2013b) COM(2013) 196: Communication from the Commission to the European Parliament and the Council: building the single market for green products facilitating better information on the environmental performance of products and organisations, Brussels
Finnveden G, Hauschild MZ, Ekvall T, Guinée J, Heijungs R, Hellweg S, Koehler A, Pennington D, Suh S (2009) Recent developments in Life Cycle Assessment. J Environ Manag 91:1-21

Frischknecht R (2006) Notions on the design and use of an ideal regional or global LCA database. Int J Life Cycle Assess 11:40-48

Galatola M, Pant R (2014) Reply to the editorial "Product environmental footprint-breakthrough or breakdown for policy implementation of life cycle assessment?" written by Prof. Finkbeiner (Int J Life Cycle Assess 19(2):266-271). Int J Life Cycle Assess 19(6):1356-1360

Kusche O, Düpmeier C, Recchioni M, Mathieux F (2012) Creating LCA data exchange networks. In: Arndt HK (Hrsg.), Proc.of the 26th Int. Conf.on Informatics for Environmental Protection, Sustainable Development and Risk Management, (EnviroInfo 2012). Shaker Verl., Aachen pp 525-532

Ossés de Eicker M, Hischier R, Kulay LA, Lehmann M, Zah R, Hurni H (2010) The applicability of non-local LCI data for LCA. Environ Impact Assess Rev 30:192-199

Pennington D, Wolf MA, Bersani R, Pretato U (2007) Overcoming barriers to the broader implementation of life cycle thinking in business and public administration. Int $\mathrm{J}$ Life Cycle Assess 12:458-460

Sanfélix J, Mathieux F, De La Rúa C, Wolf MA, Chomkhamsri K (2013) The enhanced LCA resources directory: a tool aimed at improving life cycle thinking practices. Int J Life Cycle Assess 18:273-277

Skone TJ, Curran MA (2005) LCAccess-global directory of LCI resources. J Clean Prod 13:1345-1350

Sonnemann G, Vigon B (2011) Global guidance principles for life cycle assessment databases: a basis for greener processes and products. Publication of the UNEP/ SETAC Life Cycle Initiative. UNEP, Paris

Suh S, Leighton M, Tomar S, Chen C (2013) Interoperability between ecoinvent ver. 3 and US LCI database: a case study. Int J Life Cycle Assess. doi:10.1007/s11367-013-0592-2 